\title{
Development of an inventory management system using association rule
}

\author{
Tinuke O. Oladele ${ }^{1}$, Roseline Oluwaseun Ogundokun ${ }^{2}$, Adekanmi Adeyinka Adegun ${ }^{3}$, Emmanuel \\ Abidemi Adeniyi ${ }^{4}$, Ayobami Tayo Ajanaku ${ }^{5}$ \\ ${ }^{1}$ Department of Computer Science, University of Ilorin, Ilorin, Nigeria \\ ${ }^{2,3,4,5}$ Department of Computer Science, Landmark University Omu Aran, Nigeria
}

\begin{tabular}{l} 
Article Info \\
\hline Article history: \\
Received Apr 20, 2020 \\
Revised Nov 1, 2020 \\
Accepted Jan 7, 2021 \\
\hline Keywords: \\
Apriori algorithm \\
Data management system \\
Data mining \\
Inventory system \\
Stores
\end{tabular}

Article Info

Article history:

Received Apr 20, 2020

Revised Nov 1, 2020

Keywords:

Apriori algorithm

Data mining

Stores

\begin{abstract}
Stores today still make use of manual approaches to keeping inventory which could be cumbersome. Having a computerized inventory system would make inventory management more efficient and effective. In this chapter, an Inventory Management System using Association Rule was developed which will ensure proper record keeping and keep items in stocks updated. ANGULARJS, a JavaScript framework, was used for the implementation of the system, PHP (hypertext pre-processor) was used for the backend of the system development as well as the database management, HTML was used alongside CSS for the system interface design and NoSQL database was the database used for this research. In conclusion, a computerized inventory system that had been improved using the association rule method was the resulting product useful for creating transactions, updating items in stock, record keeping, generating reports for decision making, and lastly, the system will make the stores more effective.
\end{abstract}

This is an open access article under the CC BY-SA license.

\section{Corresponding Author:}

Ogundokun, Roseline Oluwaseun Department of Computer Science Landmark University Omu Aran Kwara State, Nigeria

Email: ogundokun.roseline@lmu.edu.ng

\section{INTRODUCTION}

Inventory management system is a computer-based system meant for stalking inventory intensities [1-5], requisition (demands), transactions, and supplies. This can as well be used in the manufacturing businesses to bring about a work request, invoice of resources together with different interrelated manufacturing records. Inventory management software is an instrument that is used for consolidating inventory information [6-10] that previously was collected in hard copies format or spreadsheets. To maintain account records competently, firm owners are required to implement an excellent inventory management system. Stock in business constitutes a huge part of the investment which has to be organized in sequence to maximize to yield financial gain. Inventories are undependable and incompetent except they are well coordinated [11].

Data Mining is a concept which also refers to as knowledge discovery in database (KDD) is one of the fastest-growing fields in computer science which meets the rapidly increasing needs of information and knowledge discovery. Data mining operates with multidisciplinary domains such as database technology, information retrieval, pattern recognition, machine learning, statistics, artificial intelligence, data visualization, and high-performance computing [12,13]. Association techniques function by obtaining a set 
of robust association rules that will come up with specific designs in an unsupervised knowledge system [14, 15]. Market basket investigation operates with association rule which assists in making better inventory management systems.

The authors used ANGULARJS, PHP, HTML, CSS, and NoSQL database for the design and implementation of the inventory management system. HTML was used mainly in designing the interface of the inventory system and structuring it to be well defined. CSS was also used alongside HTML in the design of the inventory system. ANGULARJS was used for the entire development of the application while PHP was applied for the development of the entire backend of the system for the database management and APIs. NoSQL database is the database that was made use of in storing all the data that was utilized during the development of the inventory system. Lastly, the data mining approach [16-18] was used to improve the inventory management system and the approach used is the association rule which was also used for the discovery of interesting relations between variables and also used for predicting the demand for goods future. Apriori algorithm was also used for the association rule approach [19-22].

Apriori is a fundamental algorithm for mining recurring item sets in enormous databases, numerous variants of the Apriori concentrate on making better the competency of the earliest algorithm as well as the development of the algorithm for other investigated subject area. Many excellent publications summarize this topic, for example [23-29, 17] and some related works are discussed as follows:

Pragya, Madan \& Nupur [30] researched the apriori algorithm which was developed in java and was an association driving mining application. Their method could be applied to manage merchandising dealings which deliver merchants with details concerning the forecasting of product sales trends as well as consumer attitudes. Apriori algorithm was enhanced in the aspect of the time complexity, number of databases scanned, usage of memory, and the curiosity of the rules over the classical apriori algorithm. The recurred item sets revealed relies on the value of factures such as support and the number of transactions being read at a particular time, therefore, the implementation time of the algorithm relies on the transactional data group and the minimum support value.

Kharwar, Kapadia, Prajapati, \& Patel [31] utilized association rule mining usually to identify the supermarket or management of inventory strategy. Association rule mining was applied for web usage mining. Web usage mining and association rule mining were merged to enhance the substance of the serve $\log$ data. The authors made use of the Apriori algorithm as well as generated association Rule from server log which was useful in many applications such as cache for web pages, marketing, targeted advertising, and a lot more.

Oladipupo \& Oyelade [19] examined educational data mining with the use of the association rule mining method for recognizing students' failure patterns. The study recognizes the concealed correlation between the failed course of studies and recommended appropriate sources for the failure of students to increase the low capacity of students' performances. An observation was deduced that the time of implementation of the method was contrariwise proportionate to the least support because it increases as the least support diminishes were therefore established an increment in the system complexity and reaction periods just as the least support reduces. The are 19 recurring item sets and 114 rules were produced. The author, therefore, concluded that every single one of the rules with confidence 1 is a very strong rule. This invariably implies, if a student failed the determinant course of study, such student will surely fail the dependent course(s). The authors thus suggested that this rule should be enlisted in the curriculum structure. Furthermore, if the rule support is higher, this means all the courses of study being associated with by the students were all failed together by most especially the studied students. Lastly, the suggested method assisted in the curriculum structure as well as in modification to improve students' academic performance and to trim down the failure rate Adewole et al, [27].

AL-Zawaidah, Jbara \& Abu-Zanona [32] postulated an association rule mining technique that could competently ascertain the association rules in enormous databases. This postulated technique was originated from the orthodox Apriori method with several additional qualities to increase the performance of data mining. Comprehensive experimentations were implemented and the algorithm performances that is both the existing algorithm and the new algorithm were compared and the comparison showed that the study suggested method outperformed the existing methods and it could speedily discover frequent itemsets and effectively mine potential association rules.

In summary, this session had been able to cover various topics which include inventory management systems. Inventory was simply defined as stock taking and an inventory management system is a computerbased system for tracking inventory levels, sales, orders, and deliveries. The importance of the application of data mining was also pointed out. Data mining was defined as simply the process of analyzing data from different perspectives and summarizing it into useful information. Various techniques used in data mining, which include: association, forecasting, classification, and clustering, to mention a few were also discussed. Also, various algorithms have been considered, such as Apriori, SVM, K-means, and so on. Having fully 
considered those topics, it can therefore be said that application of data mining to inventory management is very important and very helpful. The world is becoming more advanced every day and it is also becoming a computerized world, extracting knowledge for already available information plays a vital role in the development of the world.

\section{RESEARCH METHOD}

In the same way that it was earlier discussed, this research focused on the development of an inventory management system and the inventory system would be able to carry out various functions such as: getting update of items in stock, keeping adequate records of product in stock, carrying out proper calculation of product sold, placing orders to suppliers via electronic-mail (e-mail), sending a notification to a user when a product is about to be sold out completely, generate report either daily report, weekly report, monthly report, yearly report or report for specific days that do not fall between those categories (for example it can be decided to generate report between Monday and Tuesday alone and so on). The system starts with a login page, where it prompts the user to input the username and password, if the username and password correspond with that already saved in the database it proceeds and is connected otherwise it stays on the login page and informs the user that a wrong username or password has been inputted, but if the user hasn't been created at all, the user would then just create an account or add a user. The login page is needed as a measure of security, so no one except authorized persons would access the inventory system. If the login is successful the user can now decide whether to add new stock, delete stock, update stock, see the goods available, purchase or sell goods or even view the sales report (either daily, weekly, monthly, or yearly).

Algorithm for the Inventory Management System

1. Start.

2. Check if the user exists.

3. If the user exists go to 6 .

4. Else

5. Create user

6. Login into the account

7. Select the desired operation.

8. If the operation selected is product go to 14 .

9. Else if the operation selected is sales go to 25 .

10. Else if the operation selected is supplier go to 35 .

11. Else if the operation selected orders to go to 41 .

12. Else Generate report.

13. Go to 43 .

14. Select the desired operation for a product.

15. If the operation selected is Add product go to 22.

16. Else if the operation selected is Manage purchases.

17. Compute the total cost of purchase

The total cost of purchase $=$ amount of product $*$ Quantity to be purchased

18. Manage purchase.

19. Go to 43.

20. Else Manage product.

21. Go to 43.

22. Enter product details.

23. Add product.

24. Go to 43.

25. Select the desired operation from sales.

26. If the operation selected is Add sales go to 29.

27. Else Manage Sales

28. Go to 43

29. Search for a product.

30. Input the description of the product

31. Input the quantity to be sold.

32. Compute the total cost of sales

The total cost of sales=amount of product*quantity sold

33. Make sales.

34. Go to 42 . 
35. Select the desired operation for supplier operation.

36. If the operation selected is Add supplier go to 38.

37. Else manage supplier go to 43.

38. Enter supplier details.

39. Add supplier go to 43.

40. Enter the details of the product to be ordered.

41. Make order go to 43.

42. Application of apriori algorithm.

43. Stop.

Figure 1 shows the developed system flowchart which explains the functionality of the system. Figure 2 shows the use case diagram for the developed application which shows all the entities involved in the development of the system and their various actions.

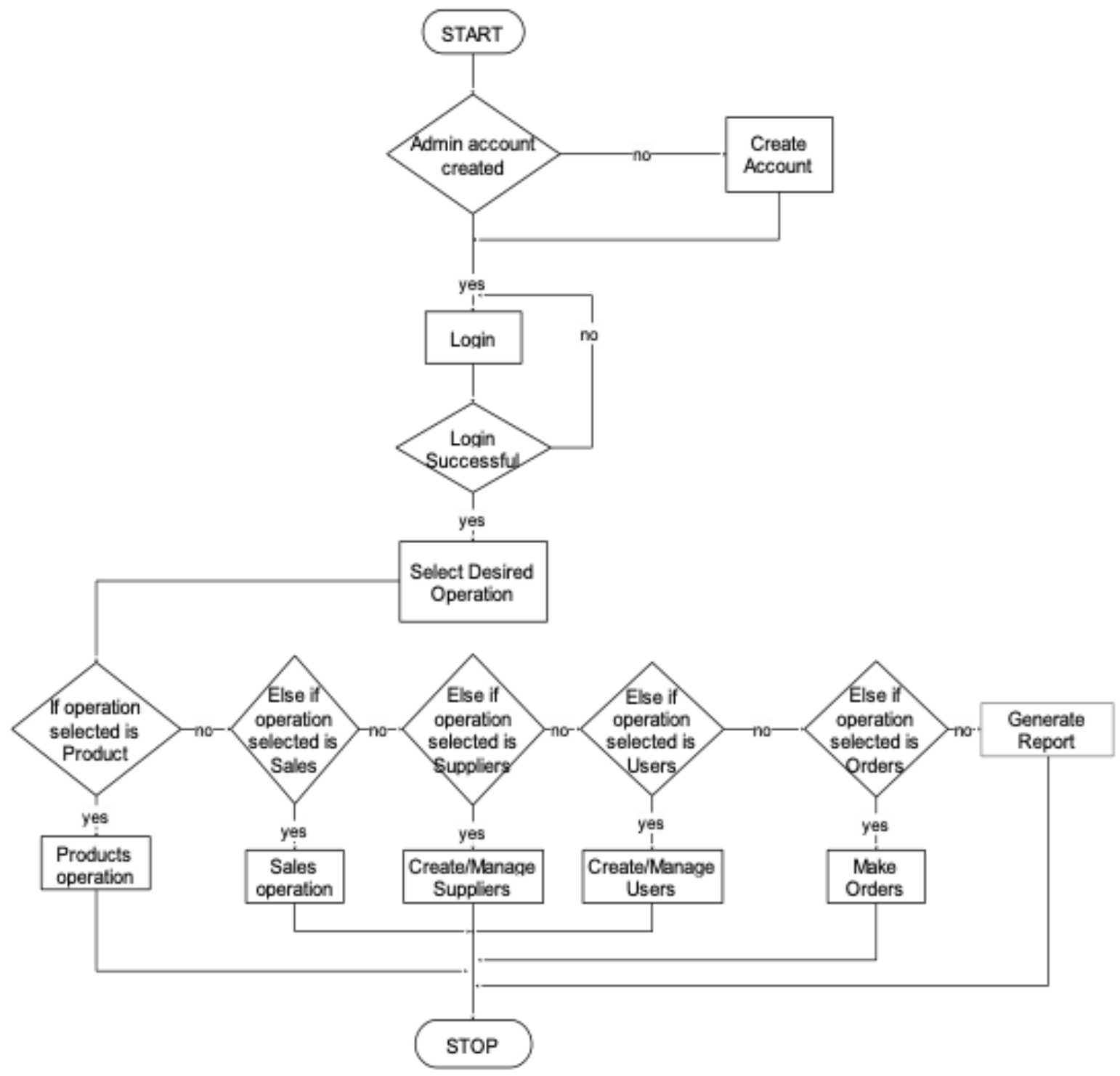

Figure 1. Program flowchart 


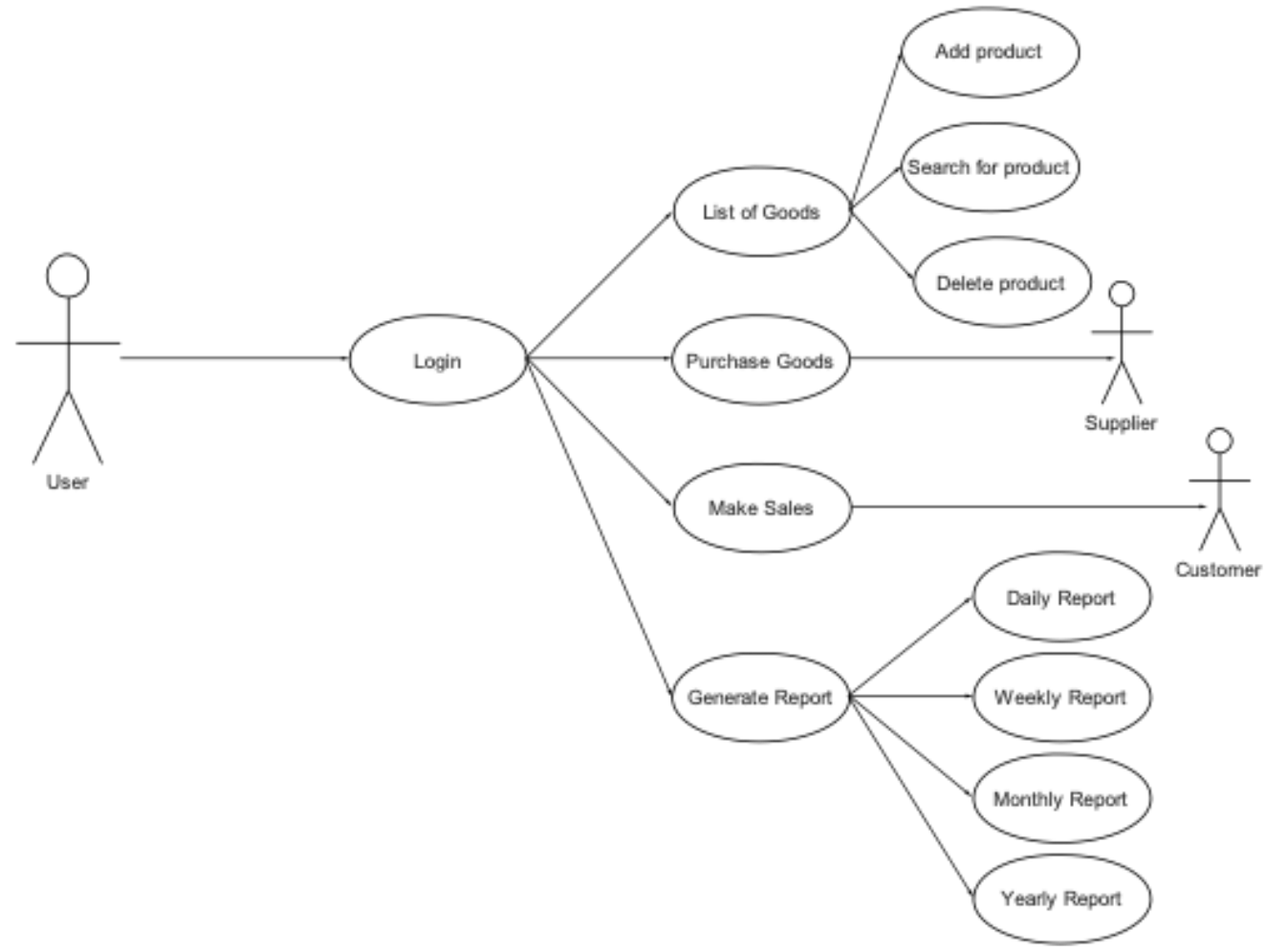

Figure 2. Program use case diagram

\section{RESULTS AND DISCUSSION}

This session discussed the implementation of the inventory management system, the various pages included in the system, the various operations carried out in the system, and also screenshots of the entire system and explanations of how they operate. The login page is needed as a measure of security. The login page is shown in Figure 3. It ensures that only authorized personnel can access the inventory system. It prompts the user for their username and password and if an account has not been created yet, the user creates an account and logs in.

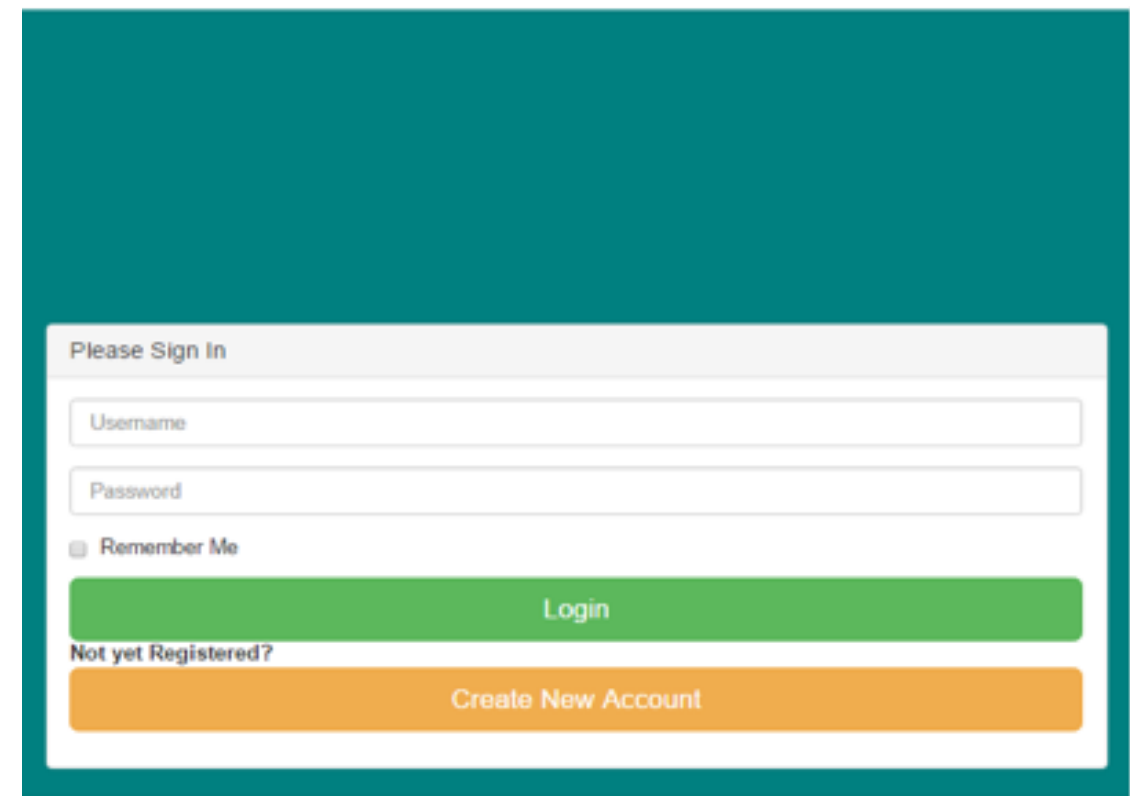

Figure 3. Login page of the inventory system 
The Registration Page is shown in Figure 4. Once the login process is successful, the user can proceed to carry out any operation required of them. Also, in creating the account the personnel would be prompted to select if he/she is a user or an admin. The user has limited features. The only thing the user can do is make sales, generate the report, and make orders. In other words, the user is like the salesperson. While the admin on the other hand serves more like the manager or business owner. The admin can do everything the user does, but with additional responsibility.

The add product page is for adding a new product to the system as shown in Figure 5. The product to be added doesn't necessarily have to be new. Also, the data mining association rule comes on the add page, after getting the frequent itemsets and generating the strong association rules, the system alerts the user or the admin personnel of products that are frequently bought together when a particular product is entered (for example, when the customer buys bread, and it is entered into the system, the system alerts the user that the customer might also be interested in buying milk and so on). The alert of frequently bought items is shown in Figure 6.

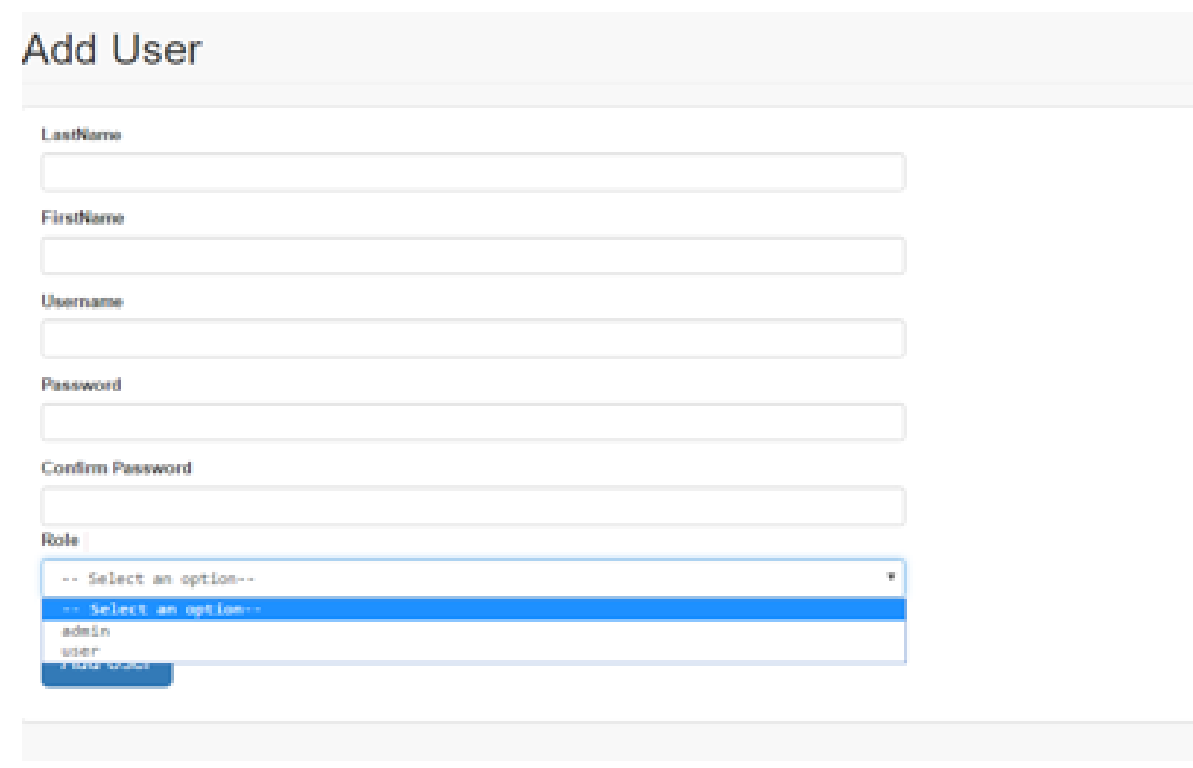

Figure 4. Registration page of the inventory system

\section{Add Products}
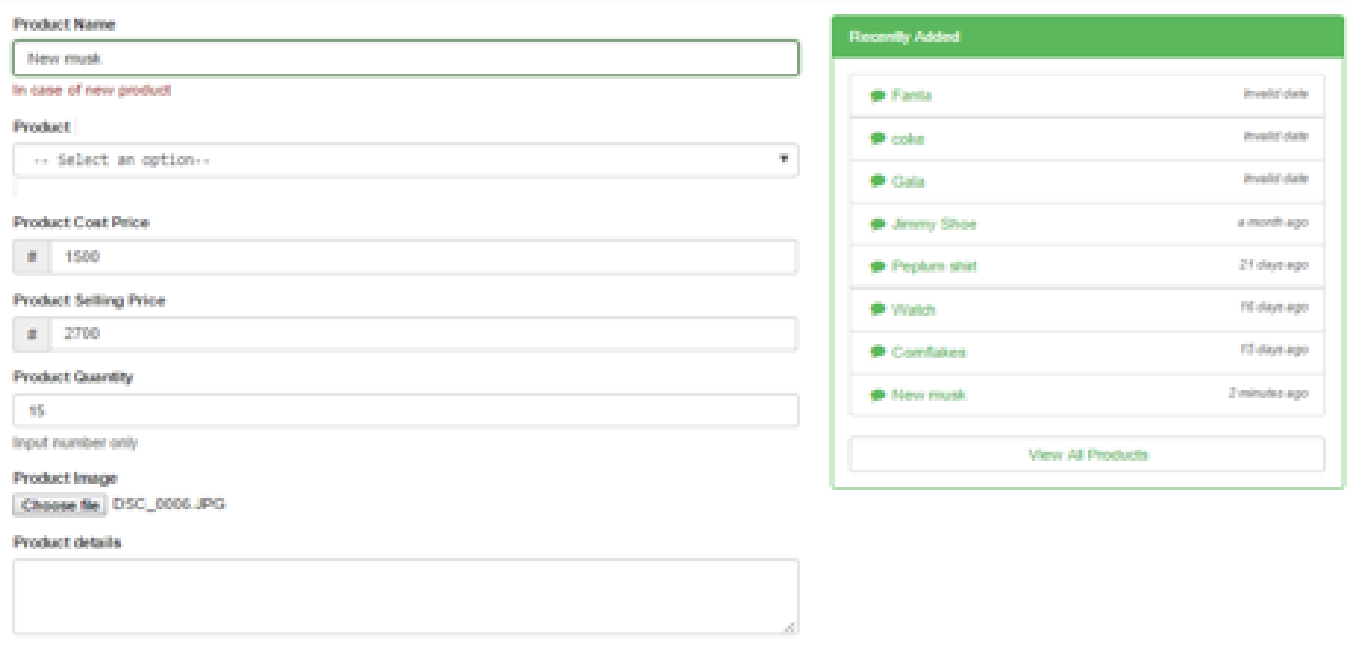

Figure 5. Add product page (in case of a new product) 
Figure 7 displays all the order that as ever been placed. The admin personnel or the manager could decide to view the report of sales or the report of purchase. The inventory system can generate a report, either daily, weekly, monthly, or even yearly. All the admin as to do is to select the start and end date of the report they would like to generate as shown in Figure 8

Once the date range has been selected, the system generates both the sales and purchase transactions that have been carried out between those dates with the start and end date inclusive as shown in Figure 9. The system lets the admin select the dates, instead of manually typing the dates in. Also, if the report has been generated, the system allows it to be printed if needed as shown in Figure 9.

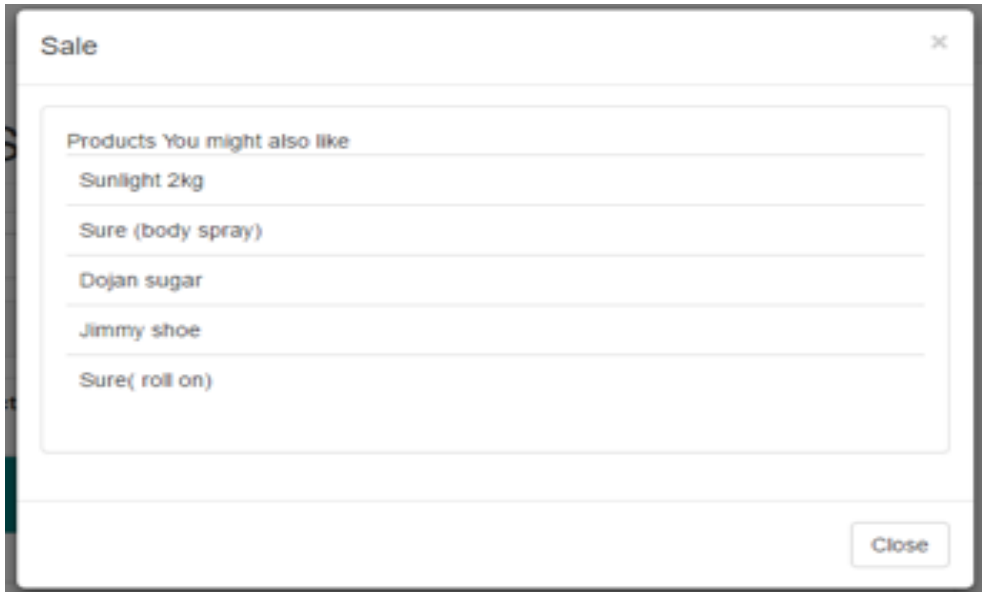

Figure 6. Alert of product frequently purchased together

\section{Order}

\begin{tabular}{|c|c|c|c|c|c|}
\hline & & a & & & \\
\hline \multicolumn{6}{|l|}{ onders } \\
\hline Prodvet Hame & Quanory Ordered & Detivery Address & suppliet & Recipem Phone Numbert & Oate Ordered \\
\hline Jaur SHoe & 2 & cmu-wran baara state & Jane stoves & BC65630183 & $2017-04-15$ \\
\hline Mnp pants & 2 & cmu-wan & Jule stores & 8669630163 & $2017-04-19$ \\
\hline New musk & 2 & omu-aran & Comerstone Limited & 8069830183 & $2017-04-19$ \\
\hline New musk & 12 & omu-aran & alle stores & 8147647041 & $2017-04-20$ \\
\hline Jimmy shoe & 12 & Ado-EDos & Julle stones & 8147647041 & $2017-04-20$ \\
\hline
\end{tabular}

Figure 7. View order page

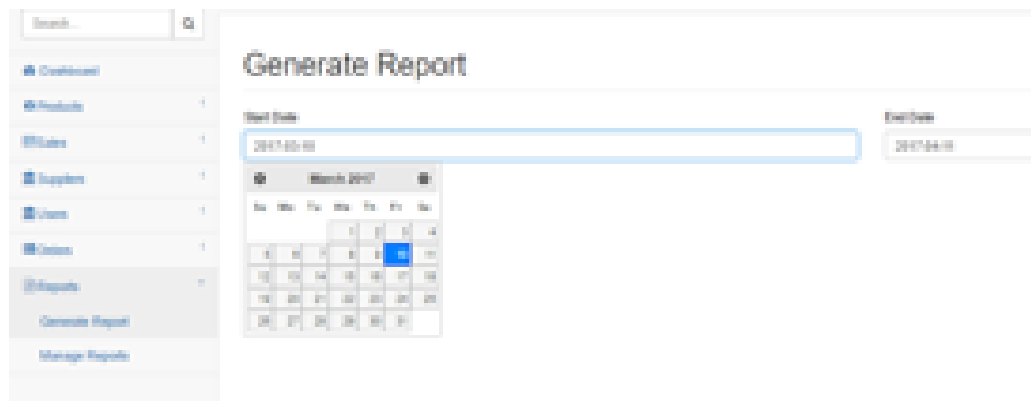

Figure 8. Generate report page 

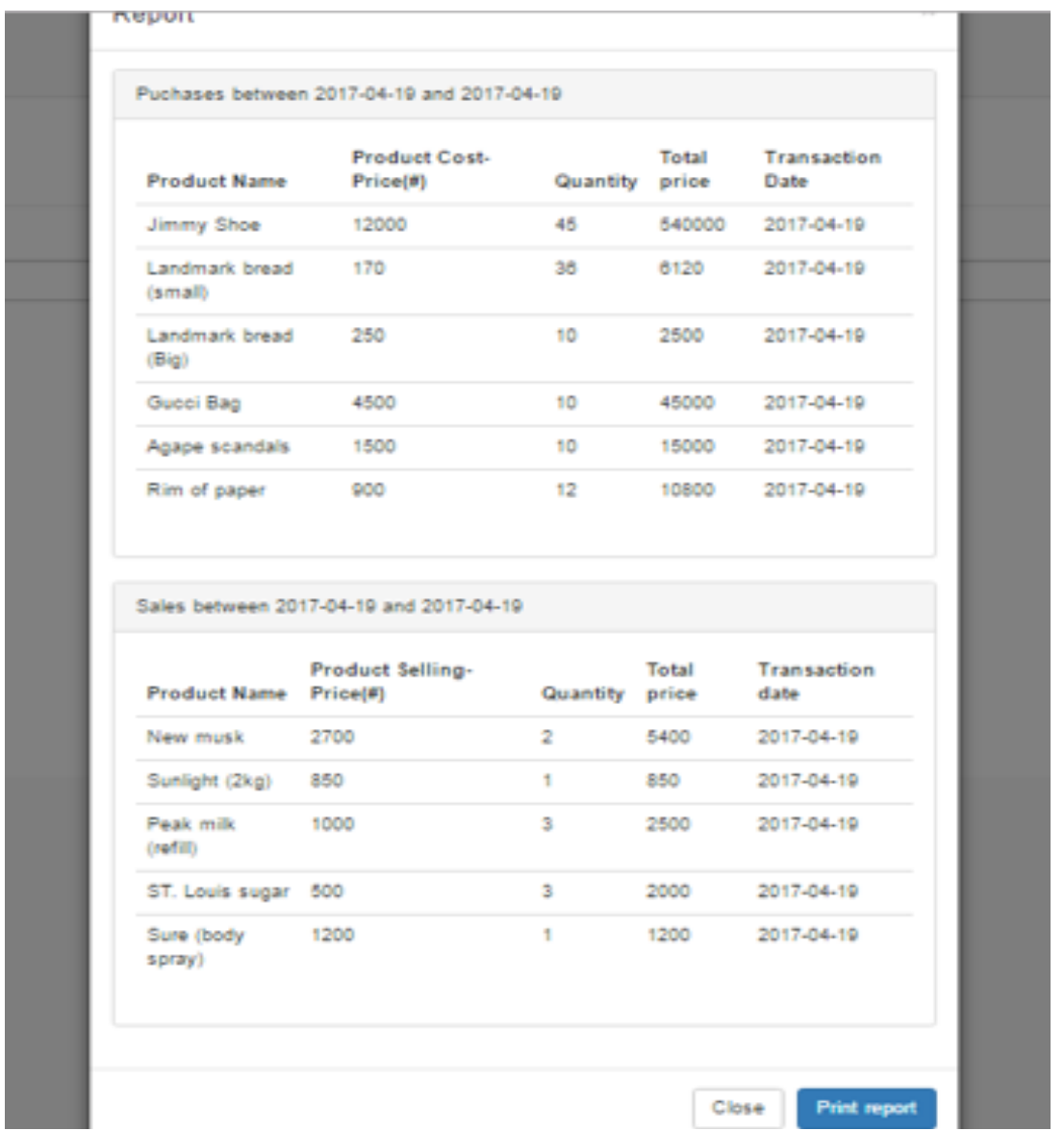

Figure 9. Report showing transaction dates of sold items

\section{CONCLUSION}

In this study, a computerized inventory system was developed and was also improved with the association rule. The system has been developed to get updates of an item in stock, to ensure proper record taking of products both to be sold and to be purchased, to know when to order for products, to make an order for products, and to generate reports from time to time when required to aid decision making process and progress of the store. The system would ensure proper inventory management and improve business performance. There will be a great improvement in inventory valuation management and control, which would lead to profit maximization. This work can still be improved by using more association rule techniques and algorithms.

\section{RECOMMENDATION}

It is advised or recommended that this project work be adopted or implemented in stores, including mini marts and supermarkets. The computerized system should replace all the manual systems in stores for stock keeping and other processes to make the stores more effective and to aid and hasten managerial decisions and update of records.

\section{REFERENCES}

[1] Macoir, N., Bauwens, J., Jooris, B., Van Herbruggen, B., Rossey, J., Hoebeke, J., \& De Poorter, E. "Uwb localization with battery-powered wireless backbone for drone-based inventory management," Sensors, vol. 19, no. 3, p. 467, 2019.

[2] Abisoye Opeyemi, A., \& Boboye Fatoba, A. B. O. "Design of a computerized inventory management system for supermarkets," 2013.

[3] Mountz, M. C., Glazkov, O., Bragg, T. A., Verminski, M. D., Brazeau, J. D., Wurman, P. R., ... \& Barbehenn, M. T. U.S. Patent No. 8,972,045. Washington, DC: U.S. Patent and Trademark Office, 2015.

[4] Olson, J. C., Kilgallon, J. L., Bowers, A., Quayle, B., Donaldson, M. D., \& Stygar, C. (2015). U.S. Patent No. 9,208,468. Washington, DC: U.S. Patent and Trademark Office. 
[5] Ahmadi, E., Masel, D. T., Metcalf, A. Y., \& Schuller, K. "Inventory management of surgical supplies and sterile instruments in hospitals: a literature review," Health Systems, vol. 8, no. 2, pp. 134-151, 2019.

[6] Kruger, G. A. "A statistician looks at inventory management," Quality progress, vol. 38, no. 2, pp. 36. K.S, 2005.

[7] Lortz, V. B., Gopalakrishnan, P. U.S. Patent No. 9,418,352. Washington, DC: U.S. Patent and Trademark Office, 2016.

[8] Iranmanesh, H., \& Kazemi, A. "A bi-objective location inventory model for three-layer supply chain network design considering capacity planning," International Journal of Logistics Systems and Management, vol. 26, no. 1, pp. 1-16, 2017.

[9] Jaggi, C. K., Pareek, S., Goel, S. K., \& Nidhi. "An inventory model for deteriorating items with ramp type demand under fuzzy environment," International Journal of Logistics Systems and Management, vol. 22, no. 4, pp. 436$463,2015$.

[10] Elsayed, K. "Exploring the relationship between efficiency of inventory management and firm performance: an empirical research," International Journal of Services and Operations Management, vol. 21, no. 1, pp. 73-86, 2015.

[11] Frank M. M., Lynch L. L., \& Rego S. O., "Tax Reporting Aggressiveness and Its Relation to Aggressive Financial Reporting," The Accounting Review: March 2009, vol. 84, no. 2, pp. 467-496, 2009. https://doi.org/10.2308/accr.2009.84.2.467

[12] Han J. \& Kamber M., 2006. Data mining: concepts and techniques. Morgan Kaufmann, [Online]. Available:http://scholar.google.de/scholar.bib?q=info:kY dwviD3IR4J:scholar.google.com/\&output=citation\&hl=d $\mathrm{e} \&$ assdt $=0 \& \mathrm{scfhb}=1 \& \mathrm{ct}=$ citation $\& \mathrm{~cd}=0$

[13] Adebiyi, M.O., Adigun, E.B., Ogundokun, R.O., Adeniyi, A.E., Ayegba, P., Oladipupo, O.O. "Semantics-based clustering approach for similar research area detection," TELKOMNIKA (Telecommunication Computing Electronics and Control), vol. 18, no. 4, pp. 1874-1883, 2020.

[14] Han, J., Kamber, M., \& Pei, J. "Data mining: concepts and techniques (2n ed.)," San Francisco, CA: Morgan Kaufmann, 2006.

[15] Kantardzic, M. "Data mining: concepts, models, methods, and algorithms," Maiden MA: Wiley-Interscience, 2003.

[16] Oladele, T.O., Ogundokun, R.O., Kayode, A.A., Adegun, A.A., Adebiyi, M.O. "Application of Data Mining Algorithms for Feature Selection and Prediction of Diabetic Retinopathy," Lecture Notes in Computer Science (including subseries Lecture Notes in Artificial Intelligence and Lecture Notes in Bioinformatics), 11623 LNCS, pp. 716-730, 2019.

[17] Dataflair Team, 2018. Data Mining Algorithms - 13 Algorithms Used in Data Mining. Retrieved on 14th August from https://data-flair.training/blogs/data-mining-algorithms/

[18] Oladele T. O., Aro T. O., Adegun A. A. \& Ogundokun R. O., "Prediction of Student's Academic Performance using k-Means Clustering and Multiple Linear Regressions," Journal of Engineering and Applied Sciences, vol. 14, no. 22 , pp. 8254-8260, 2019.

[19] Oladipupo, O. O. \& Oyelade, O. J. "Knowledge Discovery from Students' Result Repository: Association Rule Mining Approach," International Journal of Computer Science \& Security (IJCSS), vol. 4, no. 2, pp. 199-207, 2010.

[20] Joshi A. \& Sodhi J. S., "Target Advertising via Association Rule Mining," International Journal of Advance Research in Computer Science and Management Studies, vol. 2, p. 257, 2014.

[21] Fayyad U., Piatetsky-Shapiro G., \& Smyth P., "From Data Mining to Knowledge Discovery in Databases," AI Magazine, vol. 17, no. 3, pp. 37-54, 1996.

[22] Fayyad U., Piatetsky-Shapiro G., \& Smyth P., "Knowledge Discovery and Data Mining: Towards a Unifying Framework," From: KDD-96 Proceedings, Data Mining General Over view, pp. 82-88, 1996. https://www.aaai.org/Papers/KDD/1996/KDD96-014.pdf

[23] Thomas, J. K. \& Zhang, H. "Review of Accounting Studies," vol. 7, p. 163, 2002. https://doi.org/10.1023/A:1020221918065

[24] Tank, D. "Improved Apriori Algorithm for Mining Association Rules," International Journal of Information Technology and Computer Science, vol. 6, pp. 15-23, 2014. 10.5815/ijitcs.2014.07.03.

[25] Ji, Lei, Zhang, Baowen \& Li, Jianhua. "A New Improvement on Apriori Algorithm,” vol. 1, pp. 840-844, 2006. 10.1109/ICCIAS.2006.294255.

[26] Alharan, A., Alsagheer, R. \& Al-Haboobi, A. "Popular Decision Tree Algorithms of Data Mining Techniques: A Review," International Journal of Computer Science and Mobile Computing, vol. 6, pp. 133-142, 2017.

[27] Adewole K. S., Akintola A. G., Ajiboye A. R. \& Abdulsalam, S. O. "Frequent Pattern and Association Rule Mining from Inventory Database using Apriori Algorithm," African Journal of Computing \& ICT, vol. 7, no. 3, pp. 35-42, 2014.

[28] Ingle M \& Suryavanshi N. Y. "Association Rule Mining using Improved Apriori Algorithm," Interntaional Journal of Computer Application, vol. 112, no. 4, pp. 37-42, 2015.

[29] Jawad M. \& Mughal H., 2018. "Data Mining: Web Data Mining Techniques, Tools and Algorithms: An Overview," (IJACSA) International Journal of Advanced Computer Science and Applications, vol. 9, no. 6, pp. 208-215, 2015.

[30] Pragya A., Madan Y. \& Nupur A. "Study on Apriori Algorithm an its Application in Grocery Store," International Journal of Computer Application, vol. 74, no. 14, 2013.

[31] Kharwar A. R., Kapadia V., Prajapati N., \& Patel P. "Implementing APRIORI Algorithm on Web serve log," 2011.

[32] AL-Zawaidah F. H., Jbara Y. H. \& Abu-Zanona M. A., "An Improved Algorithm for Mining Association Rules in Large Databases," World of Computer Science and Information Technology Journal (WCSIT), vol. 1, no. 7, pp. 311-316, 2011. 